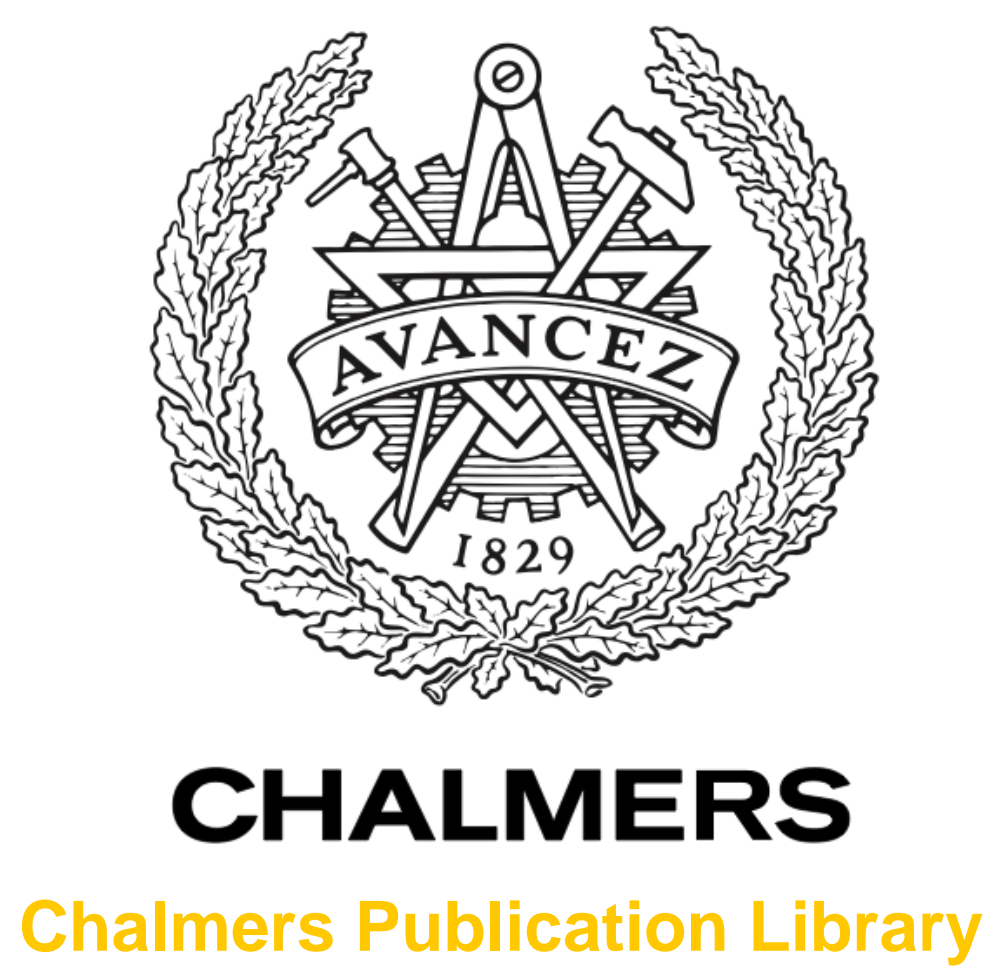

\title{
Hydrodynamic modelling of the microbial water quality in a drinking water source as input for risk reduction management
}

This document has been downloaded from Chalmers Publication Library (CPL). It is the author's version of a work that was accepted for publication in:

Journal of Hydrology (ISSN: 0022-1694)

Citation for the published paper:

Sokolova, E. ; Pettersson, T. ; Bergstedt, O. (2013) "Hydrodynamic modelling of the microbial water quality in a drinking water source as input for risk reduction management".

Journal of Hydrology, vol. 497 pp. 15-23.

http://dx.doi.org/10.1016/j.jhydrol.2013.05.044

Downloaded from: http://publications.lib.chalmers.se/publication/180267

Notice: Changes introduced as a result of publishing processes such as copy-editing and formatting may not be reflected in this document. For a definitive version of this work, please refer to the published source. Please note that access to the published version might require a subscription.

Chalmers Publication Library (CPL) offers the possibility of retrieving research publications produced at Chalmers University of Technology. It covers all types of publications: articles, dissertations, licentiate theses, masters theses, conference papers, reports etc. Since 2006 it is the official tool for Chalmers official publication statistics. To ensure that Chalmers research results are disseminated as widely as possible, an Open Access Policy has been adopted.

The CPL service is administrated and maintained by Chalmers Library. 


\title{
Hydrodynamic modelling of the microbial water quality in a drinking water source as input for risk reduction management
}

\author{
Ekaterina Sokolova $^{\mathrm{a}, *}$, Thomas J.R. Pettersson ${ }^{\mathrm{a}}$, Olof Bergstedt ${ }^{\mathrm{a}, \mathrm{b}}$ and Malte Hermansson ${ }^{\mathrm{c}}$ \\ ${ }^{a}$ Water Environment Technology, Chalmers University of Technology, SE-412 96 \\ Gothenburg, Sweden. \\ *Corresponding author. Tel. +46 31 7721929, Fax. +46 31 7722128, E-mail address: \\ ekaterina.sokolova@chalmers.se \\ ${ }^{\mathrm{b}}$ City of Gothenburg, Box 123, SE-424 23 Angered, Sweden. \\ c Department of Chemistry and Molecular Biology, Microbiology, University of Gothenburg, \\ SE-405 30 Gothenburg, Sweden.
}

\begin{abstract}
To mitigate the faecal contamination of drinking water sources and, consequently, to prevent waterborne disease outbreaks, an estimation of the contribution from different sources to the total faecal contamination at the raw water intake of a drinking water treatment plant is needed. The aim of this article was to estimate how much different sources contributed to the faecal contamination at the water intake in a drinking water source, Lake Rådasjön in Sweden. For this purpose, the fate and transport of faecal indicator E. coli within Lake Rådasjön were simulated by a three-dimensional hydrodynamic model. The calibrated hydrodynamic model described the measured data on vertical temperature distribution in the lake well (the Pearson correlation coefficient was 0.99 ). The data on the E. coli load from the identified contamination sources were gathered and the fate and transport of $E$. coli released from these sources within the lake were simulated using the developed hydrodynamic model, taking the decay of the $E$. coli into account. The obtained modelling results were compared to the observed $E$. coli concentrations at the water intake. The results illustrated that the sources that contributed the most to the faecal contamination at the water intake in Lake Rådasjön were the discharges from the on-site sewers and the main inflow to the lake - the river Mölndalsån. Based on the modelling results recommendations for water producers were formulated. The study demonstrated that this modelling approach is a useful tool for estimating the contribution from different sources to the faecal contamination at the water intake of a drinking water treatment plant and provided decision-support information for the reduction of risks posed to the drinking water source.
\end{abstract}

Key words: fecal contamination; drinking water source; E. coli; water quality modeling; MIKE 3 FM. 


\section{Introduction}

Faecal contamination of drinking water sources is a common cause of waterborne disease outbreaks (Hrudey and Hrudey 2004). Tens of thousands of people were affected by the recent outbreaks caused by the faecal contamination of water sources in Sweden, in the cities Östersund and Skellefteå in 2010 and 2011 (Skellefteå Municipality 2011, SMI 2011). The faecal contamination of drinking water sources can originate from a variety of faecal contamination sources, such as wastewater treatment plants, on-site sewer systems, emergency sewer overflows, as well as stormwater runoff from urban and agricultural areas. Therefore, the mitigation of the faecal contamination of drinking water sources and, consequently, the prevention of waterborne disease outbreaks, require the identification of contamination sources in the catchment area and the estimation of their contribution to the faecal contamination at the raw water intakes of drinking water treatment plants (WTPs).

The contribution from different sources to the faecal contamination at the raw water intake to the WTP depends on the contaminant load from the sources and on the fate and transport of the contamination within a water source. The fate and transport of faecal contamination in a water source can be simulated by means of computer models which describe the hydrodynamic situation in the water source and take the decay of microorganisms in the environment into account (e.g. Ge et al. 2012, Liu and Huang 2012, Thupaki et al. 2010, Zhu et al. 2011). In terms of drinking water management, this modelling approach can be used to prioritise mitigation measures by providing information about the contribution of different contamination sources to the faecal contamination at the raw water intake of the WTP (Sokolova et al. 2012b).

The aim of this article was to estimate the contribution from different sources to the faecal contamination at the raw water intake in a drinking water source, Lake Rådasjön in Sweden. To fulfil this aim, a three-dimensional hydrodynamic model of Lake Rådasjön was setup using the MIKE 3 FM software package. The hydrodynamic model of Lake Rådasjön was calibrated to describe the temperature distribution in the lake. The data on the contaminant load from different sources around the lake were gathered. The faecal contamination was described using the faecal indicator bacteria $E$. coli (not to be confused with the pathogenic $E$. coli bacteria). The fate and transport of the faecal indicator bacteria E. coli within the lake were simulated using the developed hydrodynamic model, taking the decay of this faecal indicator into account. The obtained modelling results were compared to the observed $E$. coli concentrations at the raw water intake of the WTP. This article investigates the influence of the different contamination sources located around Lake Rådasjön on the microbial water quality in the lake and illustrates the application of fate and transport modelling in the context of faecal contamination of drinking water sources.

\section{Material and Methods}

\subsection{Study area}

Lake Rådasjön is a dimictic lake located on the west coast of Sweden. This lake serves as the main water source for the city of Mölndal (60 000 consumers) and a reserve water source for the city of Gothenburg (500 000 consumers). The surface area of the lake is approximately 2.0 $\mathrm{km}^{2}$ and its catchment area is $268 \mathrm{~km}^{2}$. The maximum water depth is $24 \mathrm{~m}$ and the main inflow is the river Mölndalsån (Figure 1). The water flow in the river Mölndalsån varies from 
1 to $20 \mathrm{~m}^{3} / \mathrm{s}$ and the average water flow is approximately $4 \mathrm{~m}^{3} / \mathrm{s}$. The raw water intake for the city of Mölndal is located in the north-western part of the lake at a depth of $15 \mathrm{~m}$ (Figure 1).

\subsection{Contaminant load}

Lake Rådasjön is subject to contamination from various faecal sources. The concentration of $E$. coli at the raw water intake is monitored by laboratory analyses of regularly collected grab samples. The faecal contamination in Lake Rådasjön can originate from the on-site sewers located close to the lake. These on-site sewers release partly treated wastewater into a stream that enters the lake close to the raw water intakes (Figure 1). Faecal contamination also enters the lake due to emergency wastewater discharges that occur several times a year because of a hydraulic overload or technical failures within the sewer network. Moreover, faecal contamination can enter the lake through the inflow from the river Mölndalsån, which transports contamination from various sources located in its upstream catchment area. Furthermore, the faecal contamination could enter the lake with the surface runoff from a cattle grazing area located to the east of the lake and an urban area located to the north-east of the lake (Figure 1). However, based on the results of the earlier studies of this lake (Sokolova et al. 2012a, Sokolova et al. 2012b), we have concluded that the contribution from these nonpoint sources is generally much smaller than from the other identified contamination sources. Therefore, in this article, we do not take the contribution from these nonpoint sources into consideration.

To account for the influence of the on-site sewers on the microbial water quality in Lake Rådasjön, it was assumed that the on-site sewers located in the vicinity of the lake discharge untreated wastewater to the lake via a small stream, location OS, Figure 1.The discharge of wastewater from the on-site sewers was estimated based on the assumption that there are 36 people connected to these on-site sewers and that water consumption is $200 \mathrm{~L} /$ person/day.

Within the sewer network in the vicinity of Lake Rådasjön, several emergency discharges were registered during the period 2008 - 2011 by the Municipality of Härryda (Table 1). As a result of these emergency discharges, untreated wastewater entered Lake Rådasjön at different locations (Table 1): from the pumping station Pixbo Päls (location PS, Figure 1), through the stream Vällbäcken (location V, Figure 1) and through the river Mölndalsån (Figure 1).

It was assumed that the $E$. coli concentration in the untreated wastewater is $2 \times 10^{6} \mathrm{No} / 100$ $\mathrm{mL}$, which is the median value calculated based on four measurements of the $E$. coli concentration in the untreated wastewater from the Pixbo Päls pumping station.

The concentrations of $E$. coli bacteria in the river Mölndalsån were regularly measured during the period 2008 - 2011. During the period January 2008 - August 2011, the E. coli concentrations in the river Mölndalsån were measured on average two times per month, with exception of December 2009 and March 2010 when the samples were taken more frequently. Since August 2011, the samples were taken approximately once a week.

Based on the available data and the assumptions regarding the contamination sources, the load of E. coli from different contamination sources into Lake Rådasjön was calculated. 


\subsection{Model implementation}

\subsubsection{Hydrodynamic model}

To simulate the water flows in Lake Rådasjön, a three-dimensional time-dependent hydrodynamic model MIKE 3 FM (DHI 2011a) was used. The hydrodynamic model for this lake was initially set up in earlier studies (Sokolova et al. 2012a, Sokolova et al. 2012b) to simulate the situation in the lake during the year 2008. In this study, the model was further developed to simulate the situation in the lake during the years 2007 - 2011 and calibrated using the measured vertical temperature profiles in the lake.

The MIKE 3 FM model is based on the numerical solution of three-dimensional incompressible Reynolds averaged Navier-Stokes equations using Boussinesq and hydrostatic assumptions (DHI 2011a). The model consists of continuity, momentum, temperature, salinity and density equations, and is closed using a turbulent closure scheme (DHI 2011a).

The modelling domain was approximated with prisms (triangles in the horizontal plane) using a flexible mesh approach (Figure 2). The mesh consisted of 611 nodes and 1015 elements. The length of the triangles' sides varied from approximately 40 to $90 \mathrm{~m}$, and was adjusted to describe the coastline and bathymetry.

Vertically, the lake was approximated with layers of varying thickness. This thickness was adjusted to describe the physical processes in the lake, taking into account that a greater number of layers increases the computational time. Hence, the range of depth where the thermocline is formed was described with layers of $0.5 \mathrm{~m}$ thickness, to enable the correct simulation of the high temperature gradients in the thermocline. On the other hand, the upper and the lower sections of the water column, where mixed conditions prevail, were generally described with layers of greater thickness. Thus, in the model the lake is divided into 37 layers. The thickness of the two uppermost layers can vary depending on the water level in the lake (sigma-layers), while the other layers have a fixed thickness (z-layers). In an undisturbed state, the thickness of the two uppermost layers is $0.5 \mathrm{~m}$ each. These layers are followed by four layers of $1 \mathrm{~m}$ thickness each, down to a depth of $5 \mathrm{~m}$. The range of depth from 5 to $19 \mathrm{~m}$, where the thermocline is formed, is divided into twenty eight layers of $0.5 \mathrm{~m}$ thickness each; below there are two layers of $1 \mathrm{~m}$ and one layer with a thickness of $3 \mathrm{~m}$.

The model was set up to simulate the hydrodynamic situation in Lake Rådasjön in the years 2007 - 2011. The hydrodynamic situation in the lake was simulated separately for each year. The simulation for each year was started from the middle of December of the previous year (except for year 2007, when the simulation was started from January 2007), when a homogeneous temperature field of $4{ }^{\circ} \mathrm{C}$ in the domain was assumed. The initial rest conditions in the lake were defined by the constant surface elevation and the flow velocity was set to zero. The open boundary conditions were defined by the discharge into the lake from the river Mölndalsån and by the water level in Lake Stensjön, located downstream of Lake Rådasjön (Table 2). The land boundary was defined by zero normal velocity. The temperature on the open boundaries was described as zero gradients.

The model was set up to account for the hydrometeorological conditions (wind and precipitation on the lake surface), and to simulate the heat exchange between the atmosphere and the lake (Table 2, Table 3). The ice coverage of the lake during the winters (January March) of years 2009, 2010 and 2011 was taken into account; there was no ice on the lake in 2007 and 2008 (Table 2). The water density was formulated as a function of temperature. The 
bed resistance was described by a constant roughness height of $0.05 \mathrm{~m}$. The horizontal and eddy viscosity was simulated using the Smagorinsky formulation (Table 3). The vertical eddy viscosity was simulated using the k-epsilon formulation (Table 3).

The hydrodynamic model was calibrated using the measured temperature profiles in the lake (Table 3, Figure 3). In order to accurately reproduce the thickness of the epilimnion, the settings for the minimum and maximum vertical eddy viscosity were adjusted (Table 3 , Figure 3). The modelling results were particularly sensitive to the settings for the maximum vertical eddy viscosity. Furthermore, to accurately reproduce the water temperature in the epilimnion, the constants in the heat exchange module (sun constant, “a” in Ångström’s law and light extinction coefficient) were adjusted (Table 3, Figure 3).

\subsubsection{Microbial water quality model}

In order to simulate the fate and transport of the faecal contamination in Lake Rådasjön, the microbial water quality model ECO Lab (DHI 2011b) was coupled to the hydrodynamic model of the lake. ECO Lab uses flow fields from the hydrodynamic model to calculate the concentrations of the faecal indicators in the lake. The fate and transport of the faecal contamination were simulated using E. coli bacteria as a faecal indicator. In the ECO Lab model, the inactivation of the $E$. coli in the lake due to temperature and sunlight is described by Eq. 1 (Mancini 1978):

$$
\frac{d C}{d t}=-k_{0} \cdot \theta_{S}^{\text {Sal }} \cdot \theta_{I}^{\text {Int }} \cdot \theta_{T}^{(\text {Temp-20) }} \cdot C
$$

where $t$ is the time; $C$ is the $E$. coli concentration; $k_{0}\left(1 /\right.$ day) is the decay rate at $20^{\circ} \mathrm{C}$ for a salinity of $0 \%$ and darkness; $\theta_{\mathrm{s}}$ is the salinity coefficient for the decay rate; Sal (\%o) is the salinity; $\theta_{\mathrm{I}}$ is the light coefficient; Int $\left(\mathrm{kW} / \mathrm{m}^{2}\right)$ is the light intensity integrated over depth; $\theta_{\mathrm{T}}$ is the temperature coefficient for the decay rate; $\operatorname{Temp}\left({ }^{\circ} \mathrm{C}\right)$ is the water temperature.

The decay of E. coli and other faecal indicators in Lake Rådasjön was studied earlier during outdoor microcosm trials, which were performed in different seasons (March, August and November 2010) in light exposure and darkness (Sokolova et al. 2012b). Since no statistically significant differences between the persistence of $E$. coli in light and dark incubations were identified (paired samples t-test, $\mathrm{p}>0.05$ ), the light coefficient $\left(\theta_{\mathrm{I}}\right)$ in Eq. 1 was set to 1 . The salinity coefficient $\left(\theta_{\mathrm{s}}\right)$ in Eq. 1 was also set to 1, as Lake Rådasjön is a fresh water lake. The temperature $\left(\theta_{\mathrm{T}}\right)$ and the decay rate $\left(k_{0}\right)$ coefficients for $E$. coli were set to 1.04 and 0.2 , respectively.

To estimate the influence of different faecal contamination sources on the microbial water quality in Lake Rådasjön, the fate and transport of $E$. coli released from the on-site sewers, with emergency discharges and from the river Mölndalsån (see section 2.2.) within the lake were simulated for the period 2008 - 2011. To distinguish between the influences of different contamination sources on the water quality at the intake, the contamination spread from every source was modelled separately. 


\section{Results}

\subsection{Vertical temperature distribution in Lake Rådasjön}

The model was calibrated and the modelling results regarding vertical temperature distribution in Lake Rådasjön were compared with values measured on three occasions in the winter seasons and five occasions in the summer seasons (Figure 3). The comparison showed that the model described the measured data sufficiently well. The Pearson correlation coefficient was $0.99(\mathrm{p}<0.001)$, the absolute mean difference between the simulated and measured temperature was $0.3^{\circ} \mathrm{C}$ and the standard deviation of this absolute mean difference was $1.2{ }^{\circ} \mathrm{C}$. The absolute mean difference and its standard deviation accounted for $4.7 \%$ and $17.0 \%$ of the standard deviation of the measured data, respectively.

The comparison of the measured and simulated water temperatures at a $15 \mathrm{~m}$ depth (an example is shown in Figure 4) demonstrated that the model generally reproduced the timing of the autumn mixing and cooling down of the lake during October - December in a correct manner. The water temperatures during the winter season (January - March) were also well described by the model (Figure 4). However, during the warming up of the lake and the formation of the thermocline (from March/April to September) there were discrepancies (up to $3^{\circ} \mathrm{C}$ ) between the measured data and the modelling results (Figure 4). These discrepancies indicated that the simulated thermocline started on a lesser depth and ended on a greater depth or, in other words, was more stretched than the actual thermocline (Figure 3, Figure 4).

The changes in the vertical temperature distribution in the lake over time during one year are illustrated by Figure 5 .

\subsection{E. coli concentrations in Lake Rådasjön}

The load of contamination (E. coli) to Lake Rådasjön from different sources during the period 2008 - 2011 was calculated based on the available data and the assumptions described in section 2.2. (Figure $6 \mathrm{~A}$ ). The source that represented the highest total load of $E$. coli to the lake was the river Mölndalsån, followed by the emergency discharges of wastewater that entered the lake through the river Mölndalsån and the contamination from on-site sewers (Figure 6 A).

The contributions of different sources to the $E$. coli concentration at the water intake were simulated (Figure $6 \mathrm{~B}$ ). According to the modelling results, the on-site sewers on average contributed the most to the $E$. coli concentration at the water intake, followed by the river Mölndalsån (Figure 6 B). However, the river Mölndalsån caused the highest peak concentration of E. coli ( $64 \mathrm{No} / 100 \mathrm{~mL}$ ) at the water intake, followed by the emergency discharges that entered the lake through the river Mölndalsån (39 No/100 mL, Figure 6 B).

The total contribution from the identified contamination sources to the $E$. coli concentrations at the water intake was compared to the measured E. coli concentrations at the water intake (Figure 6 C). This comparison showed that the contribution from the identified sources does not fully explain the measured concentrations at the intake (Figure 6 C).

The measured E. coli concentrations at the water intake and the modelling results illustrated that the highest concentration in the lake occurred during the period October - March, while the lowest concentrations were observed in the summer months (Figure $6 \mathrm{C}$ ). 
A major factor that determines the water circulation and the spread of contamination in Lake Rådasjön is wind. This was shown by the results of an earlier study about the wind influence on the contaminant spread in this lake (Sokolova et al. 2011) and confirmed by the results of the current study. Depending on the wind speed and direction, the contamination from different sources is transported faster or slower to the water intake; in the absence of wind or when the lake is covered by ice, the contamination transport is slow.

Another important factor that influences the transport of the faecal contamination to the water intake is the vertical temperature distribution in the lake. In Lake Rådasjön, the thermocline is formed during the warmer part of the year (May - September, Figure 5 A). During this period, the thermocline reduces the vertical mixing in the lake. Therefore, the contamination that is released into the surface layers of the lake stays in the epilimnion and the spread of the contamination to the hypolimnion is limited by the thermocline (Figure $7 \mathrm{~A}$ ). The water intake is located at a $15 \mathrm{~m}$ depth; this means that under stratified conditions in the lake (May September) the raw water is taken from the hypolimnion or from the lower part of the thermocline (Figure $5 \mathrm{~A}$ ). Starting from October, the lake is well-mixed from top to bottom (Figure 5 B, Figure 7 B). The winter stratification (December and February, Figure 5 B) is weak and is unlikely to have a major impact on transport processes.

\section{Discussion}

\subsection{Modelling microbial water quality in Lake Rådasjön}

In this article, the contributions from different sources to the E. coli concentrations at the raw water intake in Lake Rådasjön were estimated using a three-dimensional hydrodynamic modelling of the fate and transport of faecal contamination. According to the modelling results, the contamination sources that contributed the most to the E. coli concentrations at the water intake were the river Mölndalsån and the discharges from the on-site sewers.

The concentrations of faecal indicator bacteria E. coli, as well as of other faecal indicators, are not directly related to the concentrations of pathogens in the environment. This is due to (i) the different fate of $E$. coli and pathogens in the environment, as well as (ii) the fact that, unlike $E$. coli, pathogens are not part of the normal faecal microbiota and are only excreted by infected individuals (Ashbolt et al. 2001, Brookes et al. 2005). However, the E. coli concentrations provide information about the degree of faecal contamination of the water source; and the presence of faecal contamination suggests that pathogens may also be present.

The fact that the simulated contribution from the identified contamination sources to the $E$. coli concentrations at the water intake does not describe some of the peaks in the measured $E$. coli concentration at the water intake (e.g. January - March 2009, end of December 2009, Figure $6 \mathrm{C}$ ) indicates that there is more contamination entering the lake than we have accounted for. This can be due to (i) underestimation of the load from the identified contamination sources and emergency discharges and/or due to (ii) the existence of unknown contamination sources or unregistered emergency discharges. This hypothesis is supported by the fact that several emergency discharges were registered after the increased $E$. coli concentrations were detected at the water intake, e.g. in December 2009 and December 2010 - January 2011 (Figure 6 A). Although the earlier studies of this lake (Sokolova et al. 2012a, Sokolova et al. 2012b) showed that the contribution from the identified nonpoint contamination sources (not accounted for in this article) was generally much smaller than 
from the identified point sources, the possibility that these nonpoint sources may have an influence on the $E$. coli concentration at the water intake cannot be completely excluded.

The low E. coli concentrations at the water intake during the summer (Figure $6 \mathrm{C}$ ) can be explained by (i) the low load of $E$. coli from the river Mölndalsån and the absence of registered emergency discharges (with the exception of the year 2010), (ii) a higher decay rate of E. coli due to higher water temperatures and (iii) the influence of the thermocline on the water circulation in the lake. The thermocline that is formed in the summer influences the spread of contamination in a water body, as it separates and prevents the mixing of the epilimnion and the hypolimnion (Boehrer and Schultze 2008). The intake is located at $15 \mathrm{~m}$ depth, i.e. below the thermocline in the hypolimnion (Figure 3). Since most of the faecal discharges to Lake Rådasjön occur on the surface of the lake, in the epilimnion, the thermocline provides some protection against fresh faecal contamination for the water intake. However, since the presence and the position of the thermocline are not constant, the protective effect of the thermocline should not be relied on by water producers in the decision-making process, in order to avoid underestimation of the risks and the need for mitigation measures.

Hydrodynamic modelling can be used to describe the microbial water quality in a water source, i.e. to estimate the concentrations of faecal indicators/pathogens at the water intake, to evaluate the variations in microbial concentrations over time and to identify periods of high risk (Brookes et al. 2006, Hipsey et al. 2008, Sokolova et al. 2012a). This information is necessary for an appropriate choice of sampling locations and frequency during monitoring programs. Furthermore, this modelling approach can be used to test various scenarios in order to examine, for example, the influence of different hydrometeorological conditions or alternative locations of contamination sources on the microbial water quality. This modelling approach provides information about the contribution from different sources to the faecal contamination at the water intake, and, therefore, it can be used to prioritise mitigation measures and to test their efficiency. The modelling approach presented in this study provides decision-support information for risk reduction management in the context of waterborne disease outbreaks caused by faecal contamination of surface drinking water sources.

\subsection{Outcomes and recommendations for water producers}

This modelling study of Lake Rådasjön was conducted as part of a project in cooperation with water producers in the cities of Gothenburg and Mölndal as well as representatives of the neighbouring municipality of Härryda. As an outcome of this project and partly due to the results of this modelling study, several positive developments took place:

- the decision has been made to remove the on-site sewers located in the vicinity of the lake and to connect the houses to the municipal sewer network;

- several malfunctions in the sewer network in the vicinity of the lake were detected and removed;

- the municipality of Härryda has established an improved reporting routine regarding the emergency discharges from the sewer network;

- the frequency of monitoring the microbial water quality in the river Mölndalsån has been considerably increased.

The results of this modelling study provided decision-support data for future revisions of the extent of the water protection area around Lake Rådasjön. In addition, the developed model can be used to simulate the effects of various events on the raw water quality in the lake in near real-time regime and even provide short-term forecasts. 
Based on the obtained modelling results, the following recommendations to water producers were formulated:

- include the catchment area of the river Mölndalsån into the water protection area;

- implement at-line monitoring of the E. coli concentrations in the river Mölndalsån, this will enable an early detection of increased loads of faecal contamination and may indicate malfunctions in the sewer network;

- improve the maintenance of the sewer network in the vicinity of the lake and the methods for the early detection of the emergency discharges in the sewer network.

\section{Acknowledgements}

This research was funded by the Graduate School on Environment and Health (Miljö och Hälsa Forskarskolan) of the Chalmers University of Technology and the University of Gothenburg, Sweden; the Swedish Water and Wastewater Association (Svenskt Vatten); the EU project VISK (Interreg IV A program). The authors are also grateful to: the Rådasjön project (SVU-project 29-122) management group for valuable discussions; the city of Gothenburg, the city of Mölndal and the municipality of Härryda for providing data for this research; DHI for providing the license for the MIKE software and modelling support.

\section{References}

Ashbolt, N., Grabow, W., Snozzi, M., 2001. Indicators of microbial water quality, in: Fewtrell, L. and Bartram, J. (Eds.), Water quality: Guidelines, standards and health. Published on behalf of WHO by IWA Publishing, London, pp. 290-316.

Boehrer, B., Schultze, M., 2008. Stratification of lakes. Rev. Geophys. 46(2).

Brookes, J.D., Davies, C.M., Hipsey, M.R., Antenucci, J.P., 2006. Association of Cryptosporidium with bovine faecal particles and implications for risk reduction by settling within water supply reservoirs. J. Water Health 4(1), 87-98.

Brookes, J.D., Hipsey, M.R., Burch, M.D., Linden, L.G., Ferguson, C.M., Antenucci, J.P., 2005. Relative value of surrogate indicators for detecting pathogens in lakes and reservoirs. Environ. Sci. Technol. 39(22), 8614-8621.

DHI, 2011a. MIKE21 \& MIKE 3 Flow Model FM Hydrodynamic Module, Short Description. Horsholm: DHI Water \& Environment. Available online at http://www.dhisoftware.com/ /media/Microsite MIKEbyDHI/Publications/PDF/Short\%20de scriptions/MIKE213 FM HD Short Description.ashx. Last accessed: 3 May 2013.

DHI, 2011b. MIKE 21/3 Ecological Modelling: MIKE21/3 ECO Lab FM Short Description. Horsholm: DHI Water \& Environment. Available online at http://www.dhisoftware.com/ /media/Microsite MIKEbyDHI/Publications/PDF/Short\%20de scriptions/MIKE213 FM EL Short Description.ashx. Last accessed: 3 May 2013.

Ge, Z., Whitman, R.L., Nevers, M.B., Phanikumar, M.S., 2012. Wave-induced mass transport affects daily Escherichia coli fluctuations in nearshore water. Environ. Sci. Technol. 46(4), 2204-2211.

Hipsey, M.R., Antenucci, J.P., Brookes, J.D., 2008. A generic, process-based model of microbial pollution in aquatic systems. Water Resour. Res. 44(7).

Hrudey, S.E., Hrudey, E.J., 2004. Safe drinking water: Lessons from recent outbreaks in affluent nations, IWA Publishing, London.

Liu, W.C., Huang, W.C., 2012. Modeling the transport and distribution of fecal coliform in a tidal estuary. Sci. Total Environ. 431, 1-8. 
Mancini, J.L., 1978. Numerical estimates of coliform mortality rates under various conditions. J. Water Pollut. Con. F. 50(11), 2477-2484.

Skellefteå Municipality, 2011. Discharges of wastewater caused Cryptosporidium infections: Report from the Department of Construction and Environment, Skellefteå Municipality on their work and conclusions. (In Swedish: "Utsläpp av avloppsvatten orsakade cryptosporidiesmittan redovisning av bygg- och miljökontorets arbete och slutsatser"). Skellefteå Municipality: Department of Construction and Environment. Available online at http://www.skelleftea.se/Bygg\%20och\%20miljokontoret/Innehallssidor/Bifogat/Slutrapport \%20bygg-\%20och\%20milj\%C3\%B6kontoret.pdf. Last accessed: 3 May 2013.

SMI, 2011. Cryptosporidium in Östersund: The work of the Swedish Institute for Communicable Disease Control with the waterborne disease outbreak in Östersund in 2010-2011 (in Swedish: "Cryptosporidium i Östersund: Smittskyddsinstitutets arbete med det dricksvattenburna utbrottet i Östersund 2010-2011"). Solna: Swedish Institute for Communicable Disease Control. Available online at http://www.smittskyddsinstitutet.se/upload/Publikationer/Cryptosporidium-i-Ostersund2011-15-4.pdf. Last accessed: 3 May 2013.

Sokolova, E., Aštröm, J., Pettersson, T.J.R., Bergstedt, O., Hermansson, M., 2012a. Estimation of pathogen concentrations in a drinking water source using hydrodynamic modelling and microbial source tracking. J. Water Health 10(3), 358-370.

Sokolova, E., Lovstedt, C., Pettersson, T., 2011. Fate and Transport Modelling of Microbial Pollution in a Lake Used as a Drinking Water Source, pp. 3171-3178, Engineers Australia, Barton, A.C.T.

Sokolova, E., Åström, J., Pettersson, T.J.R., Bergstedt, O., Hermansson, M., 2012b. Decay of Bacteroidales genetic markers in relation to traditional fecal indicators for water quality modeling of drinking water sources. Environ. Sci. Technol. 46(2), 892-900.

Thupaki, P., Phanikumar, M.S., Beletsky, D., Schwab, D.J., Nevers, M.B., Whitman, R.L., 2010. Budget analysis of Escherichia coli at a southern Lake Michigan Beach. Environ. Sci. Technol. 44(3), 1010-1016.

Zhu, X., Wang, J.D., Solo-Gabriele, H.M., Fleming, L.E., 2011. A water quality modeling study of nonpoint sources at recreational marine beaches. Water Res. 45(9), 2985-2995. 


\section{Tables}

Table 1 Emergency discharges of untreated wastewater into Lake Rådasjön

\begin{tabular}{ccccc}
\hline \multicolumn{1}{c}{ Date } & $\begin{array}{c}\text { Point of entry to Lake } \\
\text { Rådasjön }\end{array}$ & Duration, $\mathrm{h}$ & Discharge, $\mathrm{m}^{3} / \mathrm{s}$ & Volume, $\mathrm{m}^{3}$ \\
\hline 16 Jan 2008 & Pixbo päls & 4.0 & 0.0025 & 36 \\
26 Jan 2008 & Pixbo Päls & 18.0 & 0.0025 & 162 \\
10 Mar2008 & Pixbo Päls & 29.0 & 0.0025 & 261 \\
5 Oct 2008 & Pixbo päls & 4.0 & 0.0025 & 36 \\
26 Oct 2008 & Pixbo päls & 16.0 & 0.0025 & 144 \\
26 Oct 2008 & Vällbäcken & 4.0 & 0.0030 & 43 \\
14 Nov 2008 & Pixbo päls & 6.0 & 0.0025 & 54 \\
26 Oct 2009 & Vällbäcken & 6.0 & 0.0230 & 497 \\
24 Dec 2009 & Mölndalsån & 120.0 & $0.0100^{\mathrm{a}}$ & $4320^{\mathrm{a}}$ \\
2 Mar 2010 & Mölndalsån & 72.0 & $0.0100^{\mathrm{a}}$ & $2592^{\mathrm{a}}$ \\
16 Mar 2010 & Mölndalsån & $72.0^{\mathrm{a}}$ & $0.0100^{\mathrm{a}}$ & $2592^{\mathrm{a}}$ \\
30 Jul 2010 & Pixbo päls & 5.0 & 0.0019 & 34 \\
13 Aug 2010 & Pixbo päls & 2.0 & 0.0014 & 10 \\
23 Oct 2010 & Pixbo päls & 3.0 & 0.0014 & 15 \\
17 Jan 2011 & Mölndalsån & 216.0 & $0.0100^{\mathrm{a}}$ & $7776^{\mathrm{a}}$ \\
7 Sep 2011 & Pixbo päls & 3.8 & 0.0015 & 20 \\
6 Oct 2011 & Pixbo päls & 1.0 & 0.0028 & 10 \\
10 Dec 2011 & Pixbo päls & 1.5 & 0.0028 & 15 \\
\hline
\end{tabular}

${ }^{\mathrm{a}}$ Information was not registered and therefore these assumptions were made. 
Table 2 Input data for the hydrodynamic model

\begin{tabular}{lll}
\hline Type of data & Time resolution & Source \\
\hline Wind speed & 3 hours & SMHI $^{\text {a }}$ \\
Wind direction & 3 hours & SMHI $^{\text {a }}$ \\
Precipitation & 1 day & SMHI $^{\text {a }}$ \\
Air temperature & 3 hours & SMHI $^{\text {a }}$ \\
Relative air humidity & 3 hours & SMHI $^{\text {a }}$ \\
Clearness coefficient & 1 hour & SMHI $^{\text {a }}$ \\
Discharge in the river Mölndalsån & 1 day & City of Mölndal \\
Water level in Lake Stensjön & 1 day & City of Mölndal \\
Period of ice coverage & - & City of Gothenburg \\
${ }^{a}$ Swedish Meteorological and Hydrological Institute &
\end{tabular}


Table 3 Parameterisation of the hydrodynamic model

\begin{tabular}{lllll}
\hline Parameter type & Formulation & Value & Unit & Note \\
\hline Horizontal eddy viscosity & Smagorinsky formulation & & & \\
& Constant value & 0.28 & - & Default \\
& Min. eddy viscosity & $1.8 \mathrm{E}-06$ & $\mathrm{~m}^{2} / \mathrm{s}$ & $\begin{array}{l}\text { Default } \\
\text { Max. eddy viscosity }\end{array}$ \\
Vertical eddy viscosity & $1.0 \mathrm{E}+08$ & $\mathrm{~m}^{2} / \mathrm{s}$ & Default \\
& $\begin{array}{l}\text { k-epsilon formulation } \\
\text { Min. eddy viscosity }\end{array}$ & $1.0 \mathrm{E}-07$ & $\mathrm{~m}^{2} / \mathrm{s}$ & Calibr. $^{\text {a }}$ \\
& Max. eddy viscosity & $2.0 \mathrm{E}-04$ & $\mathrm{~m}^{2} / \mathrm{s}$ & Calibr. $^{\text {b }}$ \\
Bed resistance & Roughness height & & & \\
Wind friction & Constant value & 0.05 & $\mathrm{~m}$ & Default \\
Heat exchange & Constant value & 0.001255 & - & Default \\
& Constant in Dalton's law & 0.5 & - & Default \\
& Wind coefficient in Dalton's law & 0.9 & - & Default \\
& Sun constant, “a” in Ångström's law & 0.175 & - & Calibr. \\
& Sun constant, "b” in Ångström's law & 0.371 & - & Default \\
& beta in Beer's law & 0.3 & - & Default \\
& Light extinction coefficient & 0.5 & - & Calibr. \\
\hline
\end{tabular}

${ }^{\mathrm{a}}$ Calibrated value; default value: $1.8 \mathrm{E}-06 \mathrm{~m}^{2} / \mathrm{s}$

${ }^{\mathrm{b}}$ Calibrated value; default value: $0.4 \mathrm{~m}^{2} / \mathrm{s}$

${ }^{\mathrm{c}}$ Calibrated value; default value: 0.295

${ }^{\mathrm{d}}$ Calibrated value; default value: 1.0 


\section{Figures}

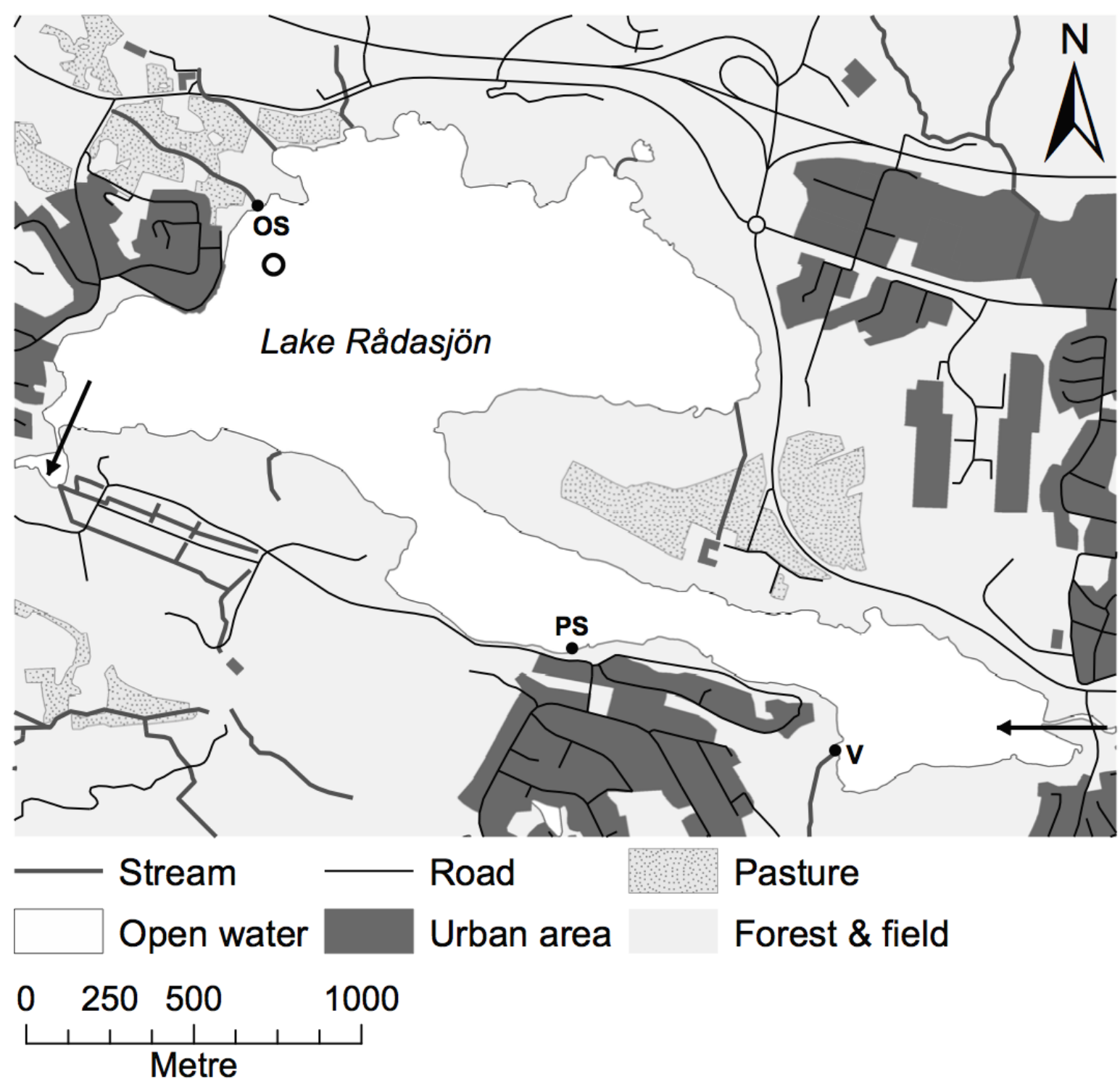

Figure 1 Map of Lake Rådasjön. Symbols: OS - the discharges from on-site sewers, PS - the pumping station Pixbo Päls, V - the stream Vällbäcken that transports emergency wastewater discharges; black arrows represent the inflow to the lake from the river Mölndalsån and the outflow from the lake to Lake Stensjön; the circle represents the location of the raw water intake. 


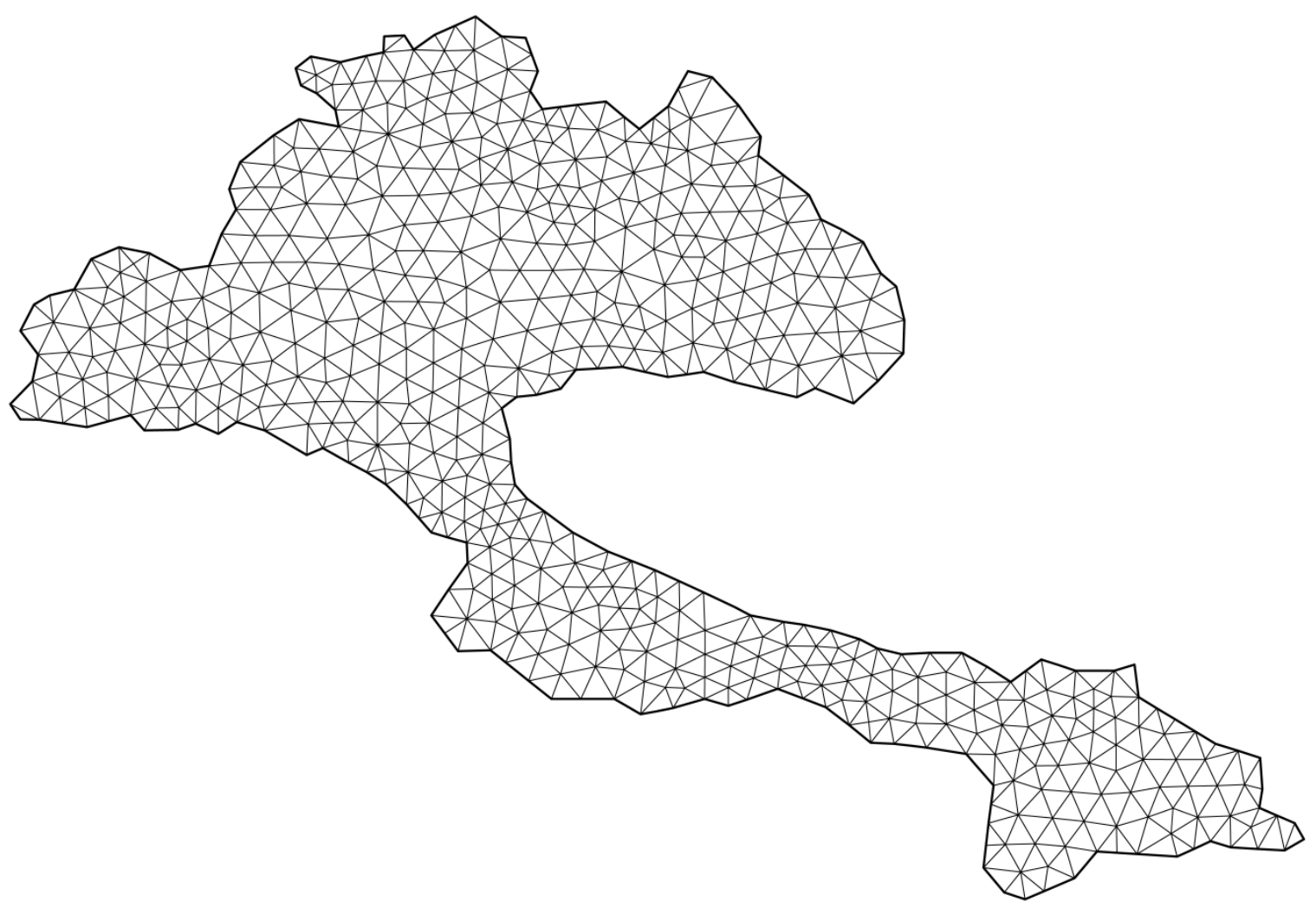

Figure 2 Computational mesh for the hydrodynamic model of Lake Rådasjön 
2007

Temperature, ${ }^{\circ} \mathrm{C}$

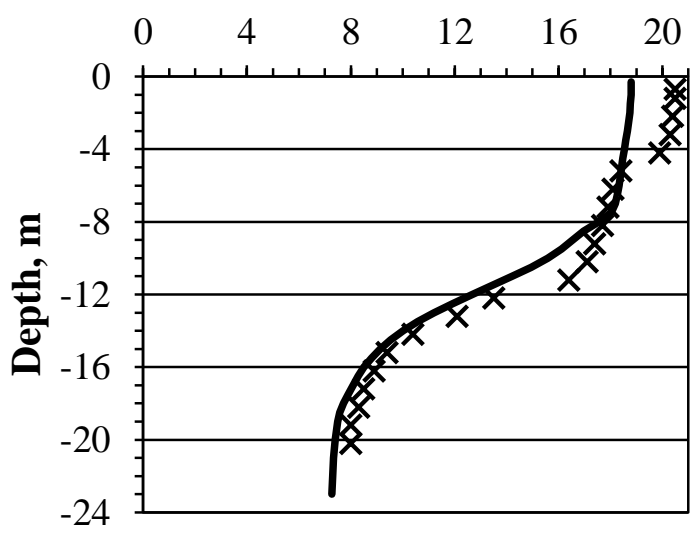

2009

Temperature, ${ }^{\circ} \mathrm{C}$

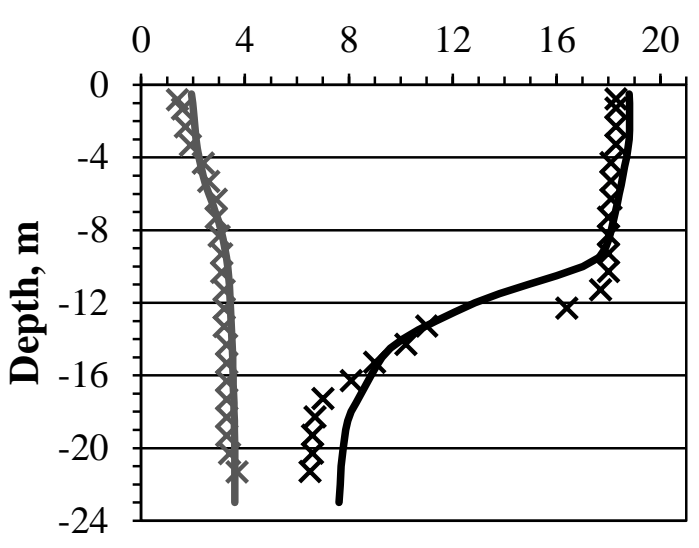

2011

Temperature, ${ }^{\circ} \mathrm{C}$

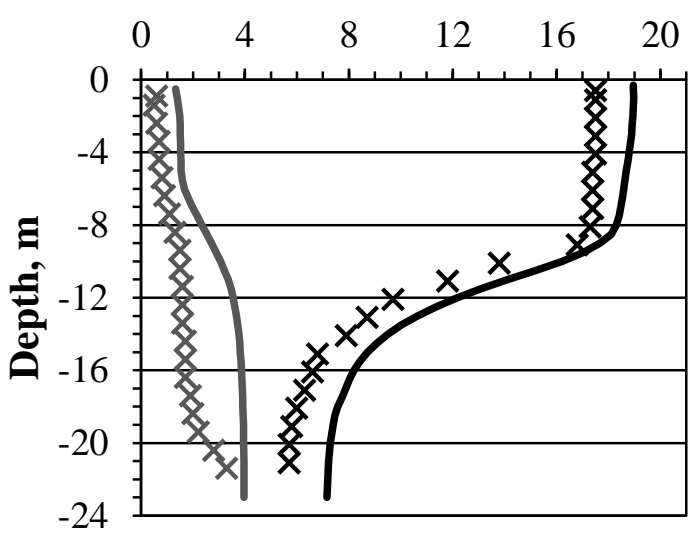

2008

Temperature, ${ }^{\circ} \mathrm{C}$

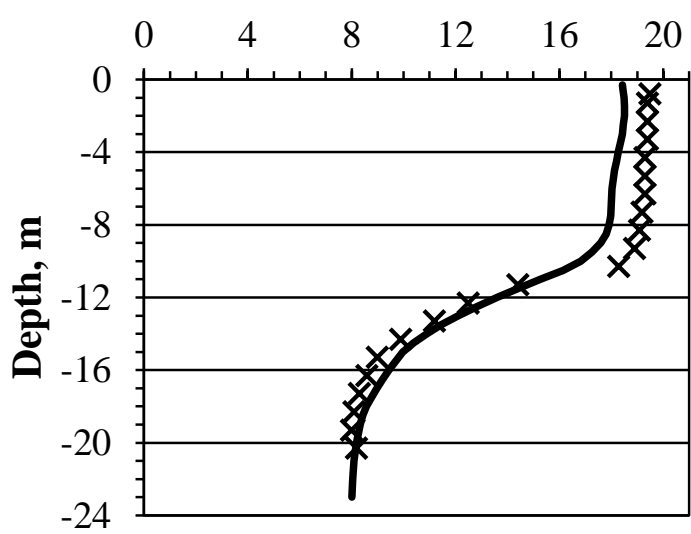

2010

Temperature, ${ }^{\circ} \mathrm{C}$

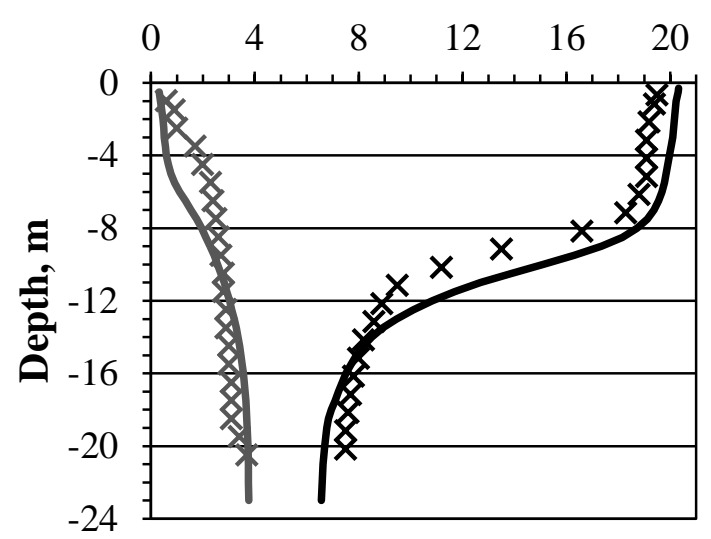

Figure 3 Measured (crosses) and simulated (lines) temperature profiles in Lake Rådasjön. The winter temperature profiles (grey colour) were measured on 25 February 2009, 9 March 2010 and 24 February 2011. The summer temperature profiles (black colour) were measured on 15 August 2007, 22 August 2008, 19 August 2009, 13 August 2010 and 31 August 2011. The data on measured temperature profiles in the lake were provided by the Göta älv Water Management Association (GÄVVF). 
2009

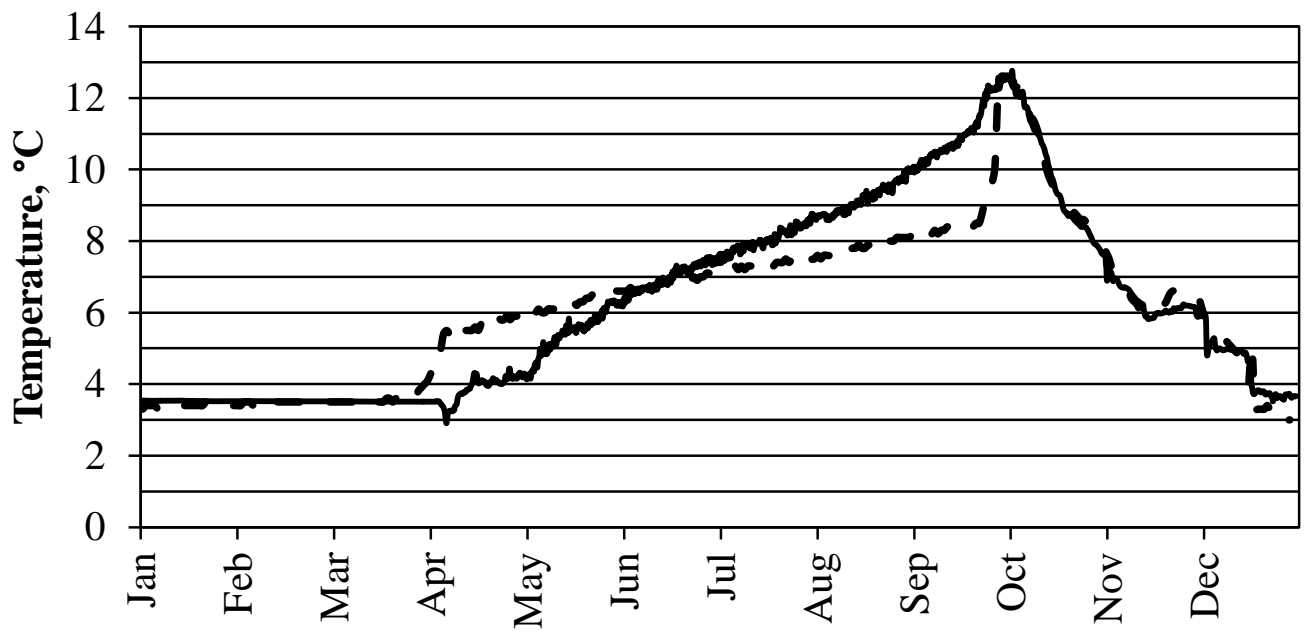

Figure 4 The measured (dotted line) and simulated (black line) water temperatures at the water intake located at a $15 \mathrm{~m}$ depth (the measured data were provided by the city of Mölndal). 


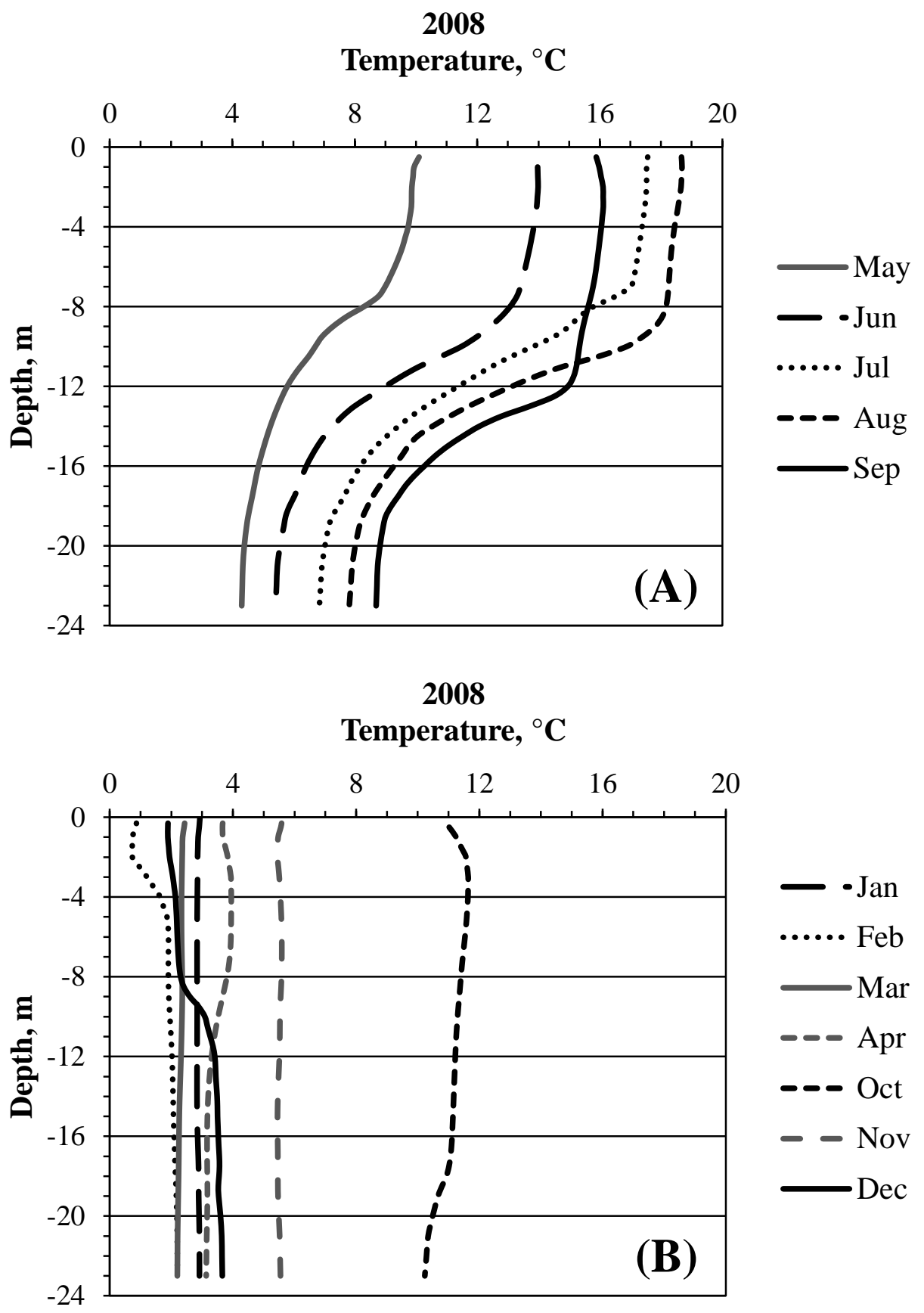

Figure 5 Modelling results: the vertical temperature distribution in Lake Rådasjön on the 15th of every month during 2008; (A) months with stratified conditions, (B) months with mixed conditions. 


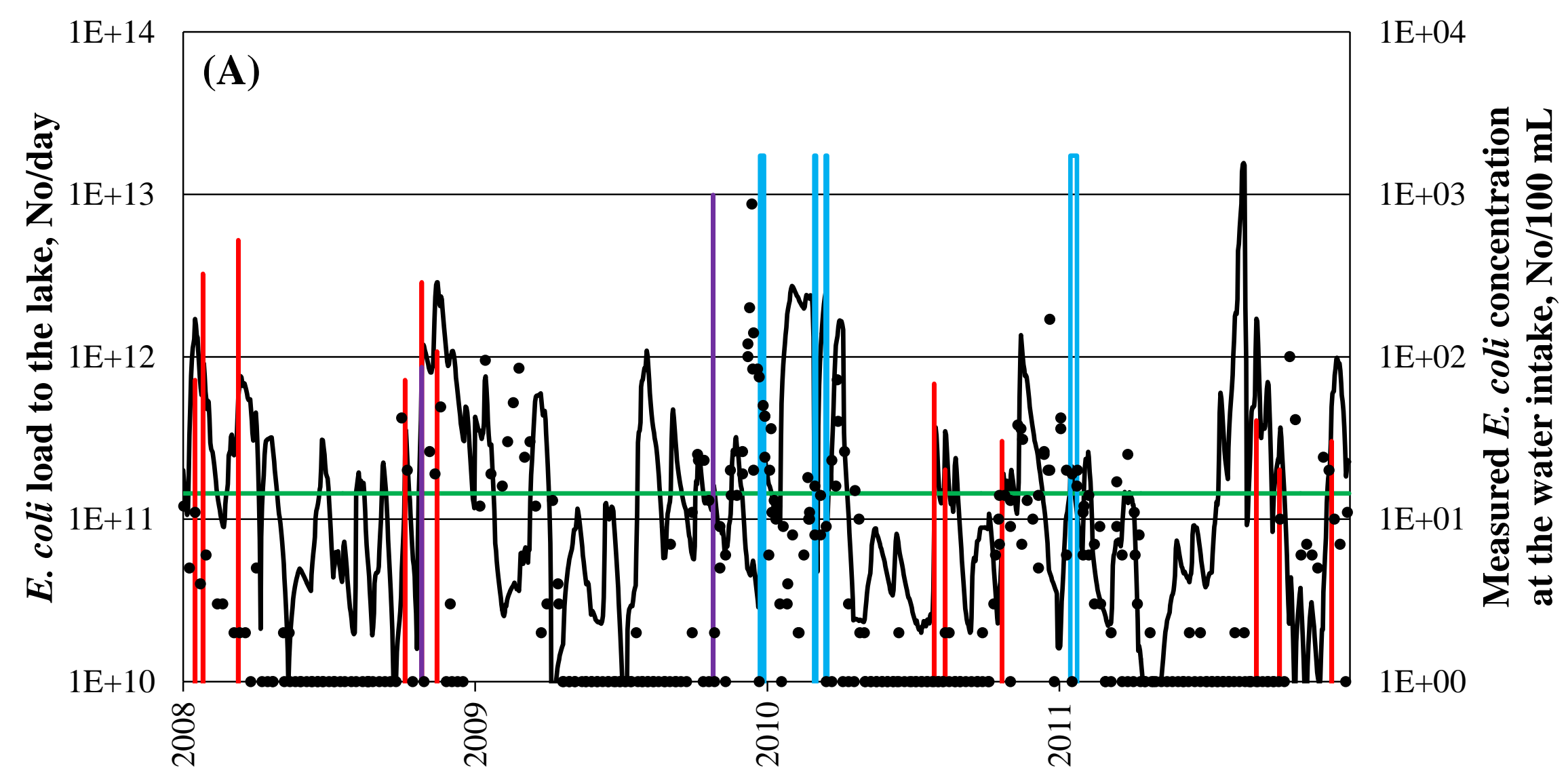




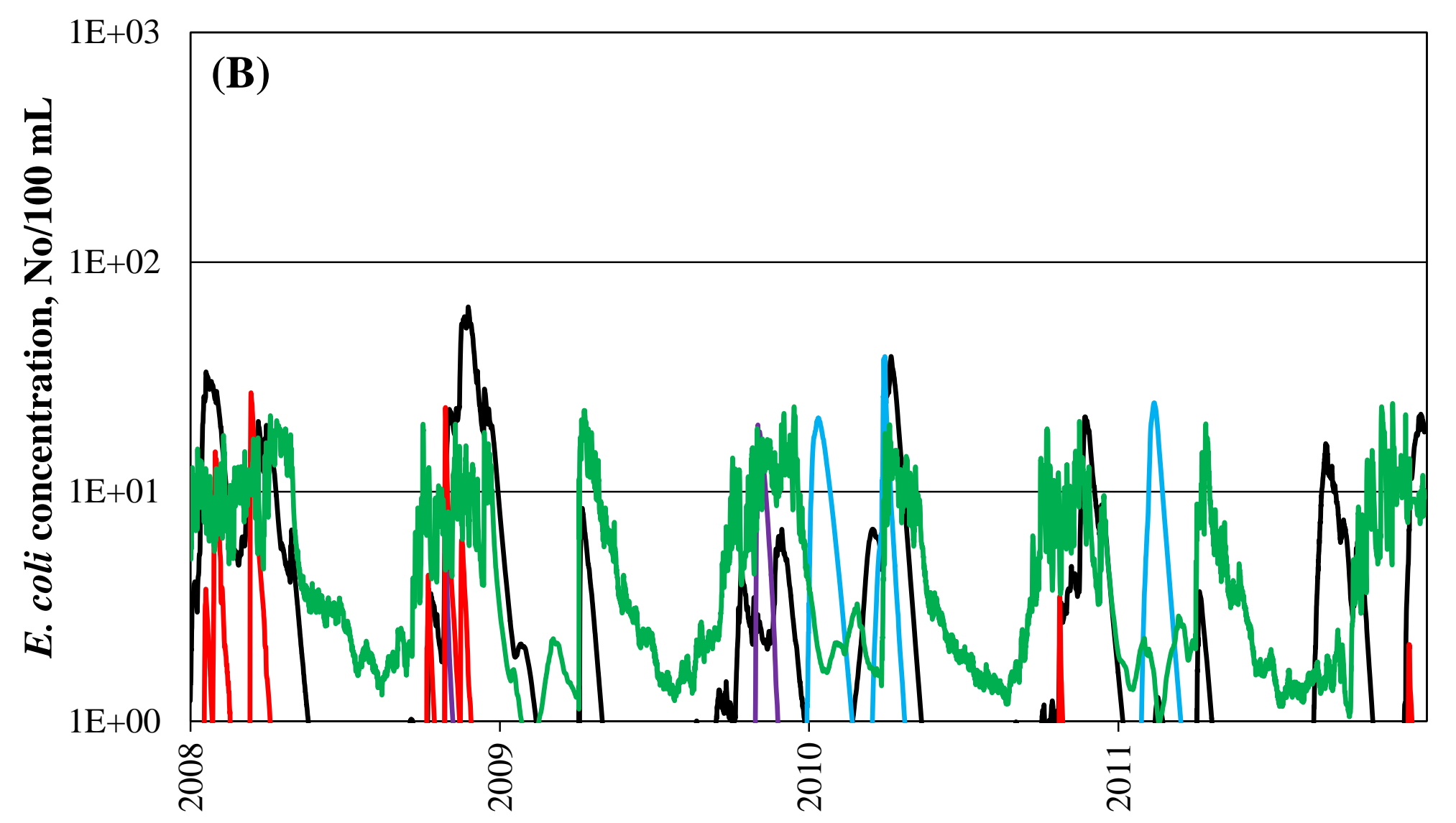




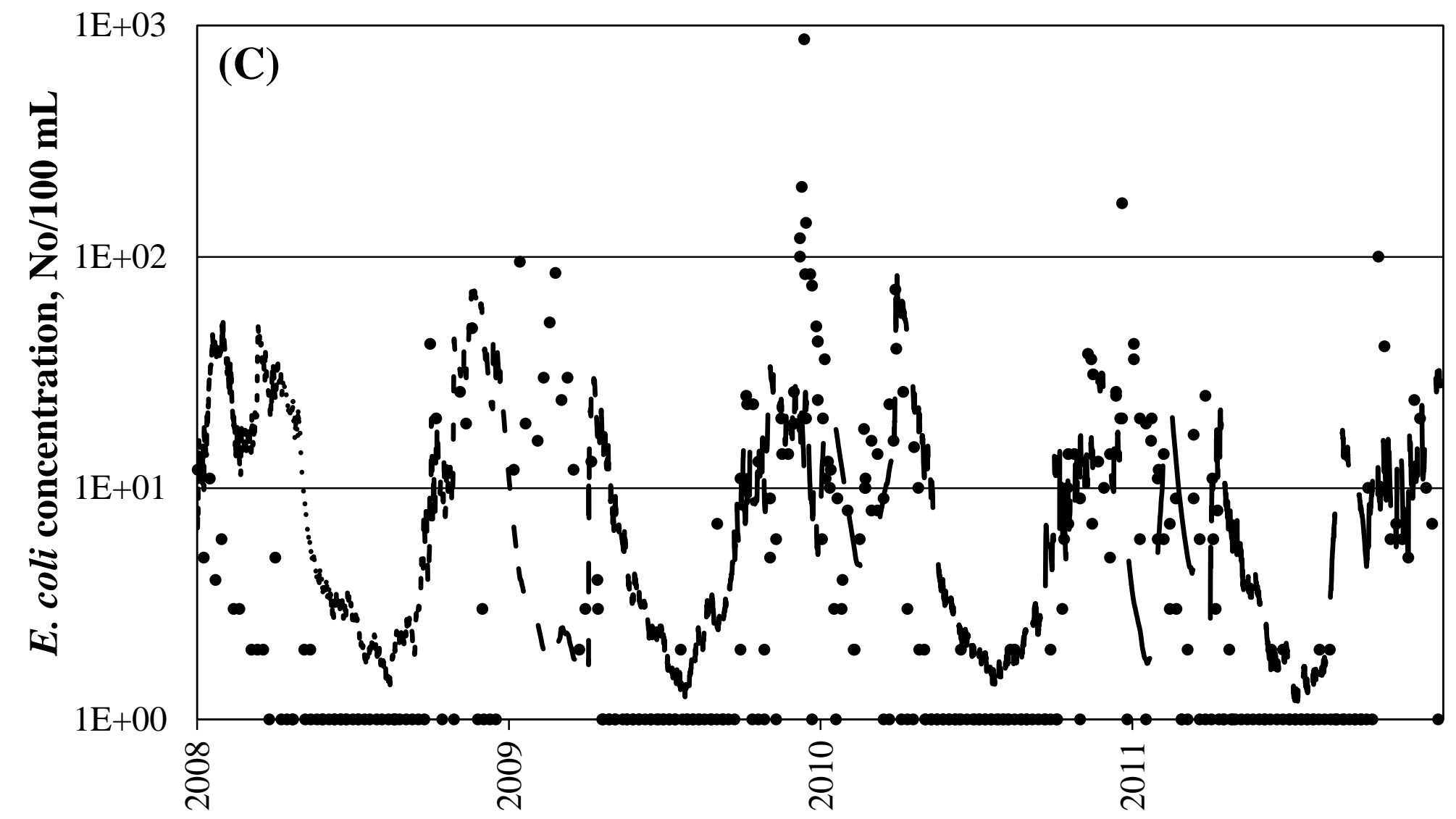

Figure 6 (A) Measured E. coli concentrations at the water intake and E. coli load from the contamination sources to Lake Rådasjön. (B) Modelling results: the contribution of the different contamination sources to the E. coli concentrations at the water intake in Lake Rådasjön. (C) The total simulated contribution of the different contamination sources to the $E$. coli concentration at the water intake and the measured $E$. coli concentrations at the water intake. Symbols in Figures (A), (B) and (C): green - the on-site sewers, red - the pumping station Pixbo Päls, black the river Mölndalsån, purple - the emergency discharges through the stream Vällbäcken, blue - the emergency discharges through the Mölndalsån, black dots - laboratory analyses of the E. coli concentrations in grab samples. 


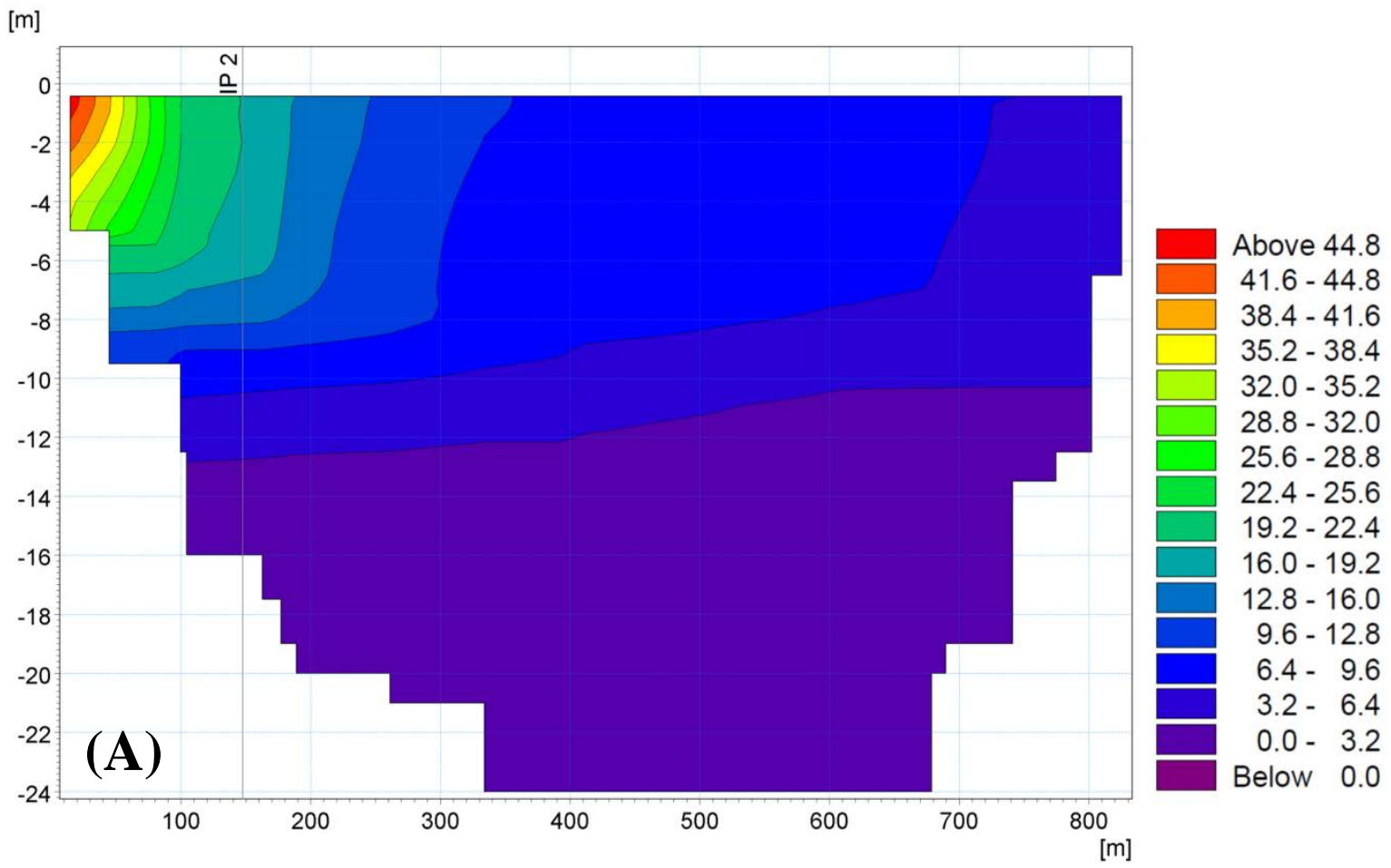

[m]

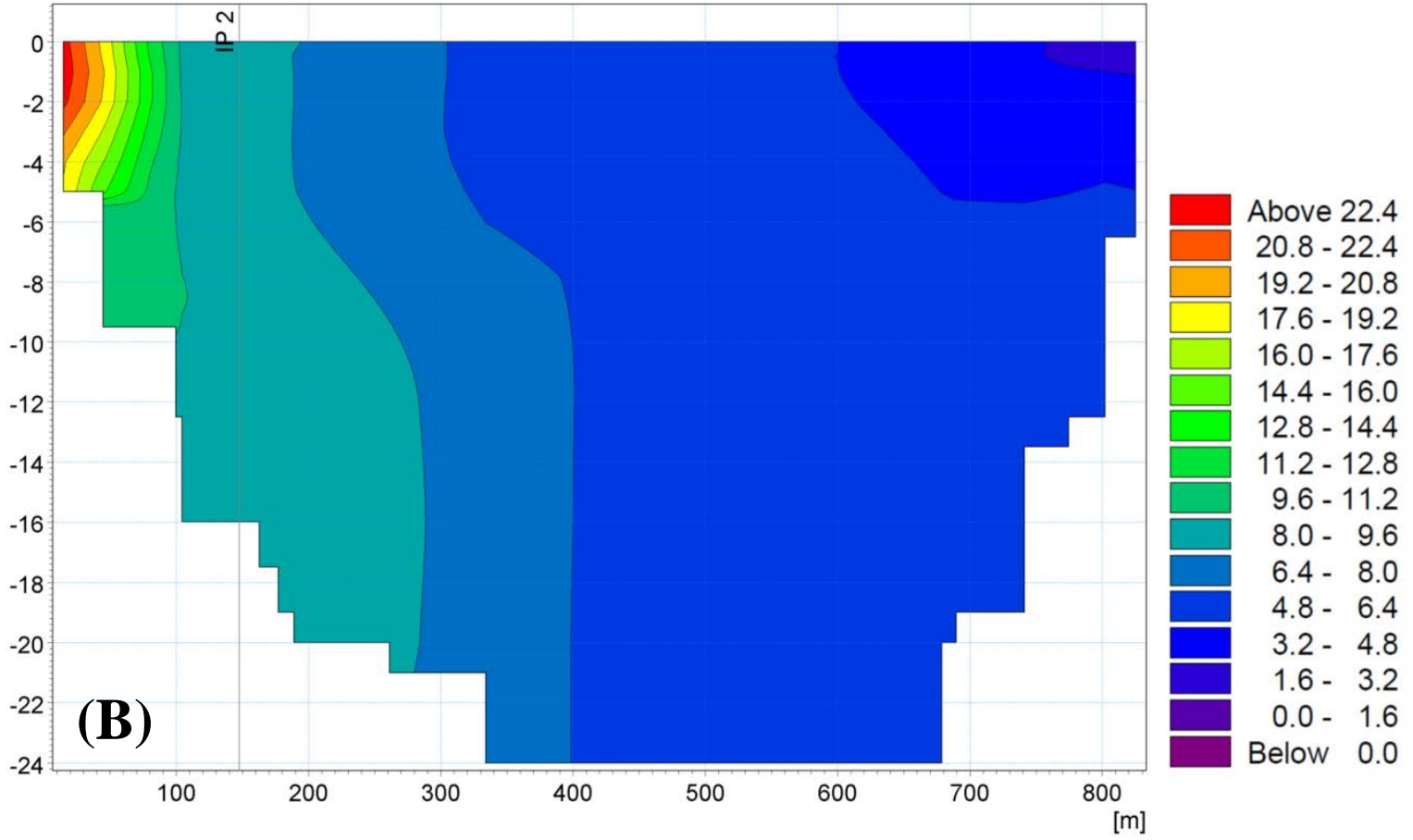

Figure 7 Modelling results (cross-section): the spread of the faecal contamination (E. coli, No/100 mL) from the on-site sewers within Lake Rådasjön on (A) 15 July 2008 and (B) 15 November 2008. The cross-section starts at the location of the on-site sewers ("OS" in Figure 1) and continues through the location of the water intake ("IP 2") to the edge of the peninsula in the east (see Figure 1). 